\title{
Development of The E-Personal Safety Logbook (e-PSLB) Optimization Registration Process of Personnel Onboard FSRU
}

\author{
Faishal Rachman ${ }^{1}$, Andri Cahyadi ${ }^{2}$, and Rachmat Afriyanto ${ }^{2}$ \\ ${ }^{1}$ Division of Commercial, PT PGN LNG Indonesia, Jakarta \\ ${ }^{2}$ Department of HSSE, PT PGN LNG Indonesia, Jakarta \\ e-mail: faishal.rachman@pgnlng.co.id
}

\begin{abstract}
PT PGN LNG Indonesia (PGN LNG) aims to develop the LNG business that consists of natural gas liquefaction, LNG storage and shipment, and regasification to natural gas. Since July 2014, PGN LNG has been operating Floating Storage Regasification Unit (FSRU) which located $21 \mathrm{~km}$ offshore from Lampung. In order to support PGN LNG operation on FSRU related to requirement of Health, Safety, Security and Environment (HSSE) data of personnel onboard vessel, PGN LNG developed a system to mitigate potential hazards and risk that called Personal Safety Logbook (PSLB). PSLB consist of personnel data of identity, basic sea survival certificate, and health. Since July 2014 to December 2016 registration of PSLB data done manually by collecting registration paper filled by applicant and approved by management. Based on the evaluation conducted by management, it showed implementation of manual registration requires long approval time. In this case, PGN LNG require system that reduces approval time and provides comprehensive information. In July 2016, Department HSSE has been developed an online ePSLB Application that started to be implemented in January 2017. Until December 2019 it has already done 846 PSLB submissions with an average 282 per year. Based on the analysis of the data, it showed that if still using manual PSLB Registration in the period of January 2017 until December 2019 it is required total cost of $R p .333,630,000$ in three years. Whereas when compared with the use of e-PSLB within same period, it is required a total cost of $R p 176,846,741$. In addition, reviewed from the completion duration of one Manual PSLB takes 3 hours 15 minutes, while e-PSLB only takes 45 minutes. Therefore, based on the results of the analysis of e-PSLB proved effective and efficient in assisting operation excellence of PGN LNG.
\end{abstract}

Keywords-Application, Optimization, Registration, Vessel.

\section{INTRODUCTION}

$\mathrm{T}$ HE world changes every day along with the development of human civilization [1]. Therefore, technical development and production technology have also changed. The Industry Revolution 4.0 is a model that shows how industrial production follows the latest developments and changes over time that manifest itself in changes in data, technology, automation and digitalization. The use of digital technology is causing drastic changes in business models.

The fourth industrial revolution was based on data [2]. The way it can be collected and analyzed, and used to make right and developing decisions, has become a competitive factor. The source of competitive advantage, therefore, will not only be production on a coordinated or completely new basis (for example, additive production), but also the insertion of products with digital services (for example, if a failure occurs, the machine itself shows which replacement part is must be carried), that is, how companies filter relevant information from data generated to support decision making PT PGN LNG Indonesia (PGN LNG) aims to develop the LNG business that consists of natural gas liquefaction, LNG storage and shipment, and regasification to natural gas. Since July 2014, PGN LNG has been operating Floating Storage Regasification Unit (FSRU) which located $21 \mathrm{~km}$ offshore from Lampung. In order to support PGN LNG operation on FSRU related to requirement of Health, Safety, Security and Environment (HSSE) data of personnel onboard vessel, PGN LNG developed a system to mitigate potential hazards and risk that called Personal Safety Logbook (PSLB). PSLB consist of personnel data of identity, basic sea survival certificate, and health. Since July 2014 to December 2016 registration of PSLB data done manually by collecting registration paper filled by applicant and approved by management. Based on the evaluation conducted by management, it showed implementation of manual registration requires long approval time. In this case, PGN LNG require system that reduces approval time and provides comprehensive.

The objective of this study is to discover how companies operating in e-PSLB to support their operation processes, enable easiness of PSLB submission, and reduce submission time in order to tackle critical issues during adaptation of ePSLB. Creation of E-PSLB as well to accommodate internet facilities that has been able to access by all parties. In addition, it could enable real time monitoring which person that has been authorized to be on board FSRU.

\section{METODOLOGY}

\section{A. Development of e-PSLB}

Since June 2016 HSSE Department has started to develop e-PSLB a web application system that can simplify and streamline the implementation of HSSE in the internal PGN LNG. This initiative was initiated when in the process of registering passengers who would aboard to the FSRU was still done manually by collecting PSLB forms and attaching hardcopy such as Copy of ID, Scan of Basic Sea Survival Certificates that are still valid and Proof of implementation of Medical Check Up (MCU) for at least 1 (one) year. These data after being collected must be verified and approved by manager that the personnel authorized or not to be on board FSRU. The development Model of e-PSLB is based on Waterfall model that starts from the early stages of the development of the system until the final stage of system development on the maintenance phase. The next stage will 
Table 1.

Actors involved

\begin{tabular}{|c|c|c|}
\hline No. & Actor & Description \\
\hline 1 & Admin & $\begin{array}{l}\text { Admins have the highest } \\
\text { access rights to manage } \\
\text { accounts and information that } \\
\text { the system will need }\end{array}$ \\
\hline 2 & $\begin{array}{c}\text { Manager (HSSE Manager, } \\
\text { Operation \& Maintenance } \\
\text { Manager, Marine Operation } \\
\text { Manager) }\end{array}$ & $\begin{array}{l}\text { Manager can register } \\
\text { themselves to create an } \\
\text { account, can log in to the } \\
\text { system, can change the } \\
\text { password and approve for a } \\
\text { PSLB submission }\end{array}$ \\
\hline 3 & User & $\begin{array}{l}\text { Users can register themselves } \\
\text { to create an account, can log in } \\
\text { to the system, can change the } \\
\text { password, Submit for a PSLB }\end{array}$ \\
\hline
\end{tabular}

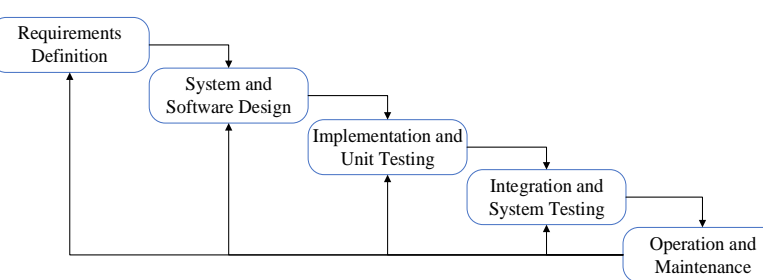

Figure 1. Waterfall model.

not be implemented before the previous stage is completed and cannot return or repeat to the previous stage [3]. Waterfall modeling steps can be seen in Figure 1.

The stages of software modeling using waterfall models consist of needs, system and software design, unit testing and implementation, system testing and integration, and program and maintenance implementation [3].

1) System Needs Analysis

To understand the functionality of the software to be built, analysis must understand the information as well as the behavior that the system must have. In the analysis of this need is a search for the needs needed and must be owned by the system so application can obtain the desired results. This input Data is being obtained from the Admin, Manager (HSSE manager, operation \& maintenance manager and marine operation manager) and from the User (permit applicant). For admin data collection is profile information, both manager as the approver of e-PSLB and User (permit applicant). The side of the head department is obtaining the identity information of applicant User consent. User-side data input in the form of identity that will be entered in the application of PSLB approval.

The actors who play roles in the Web e-PSLB and the activity settings that can be performed by each actor shown in Table 1.

\section{2) System Design Process}

The next step is system design process as a basic overview of system shapes. In doing system design, there are several things that must be created that are design of work process, database design and system display design. Modeling work process design using structured methods, namely the context Diagram and DFD (data flow diagram) Level 1.

Design process of the e-PSLB, i.e.:

1. Process 1 (Admin) is the process of adding user account and management of user data by Admin. In this process, the process of managing data by this Admin can be divided into the process of viewing user data and deleting user data.

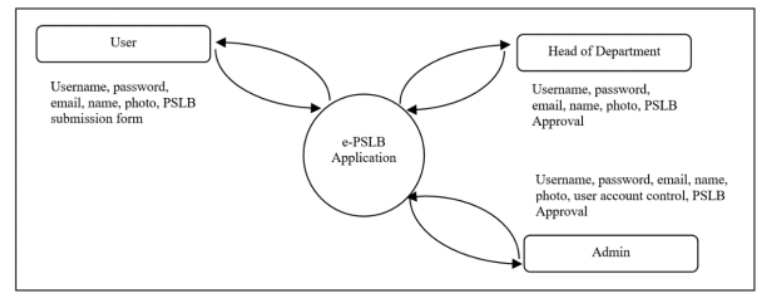

Figure 2. Data Flow Diagram Level 1 e-PSLB.

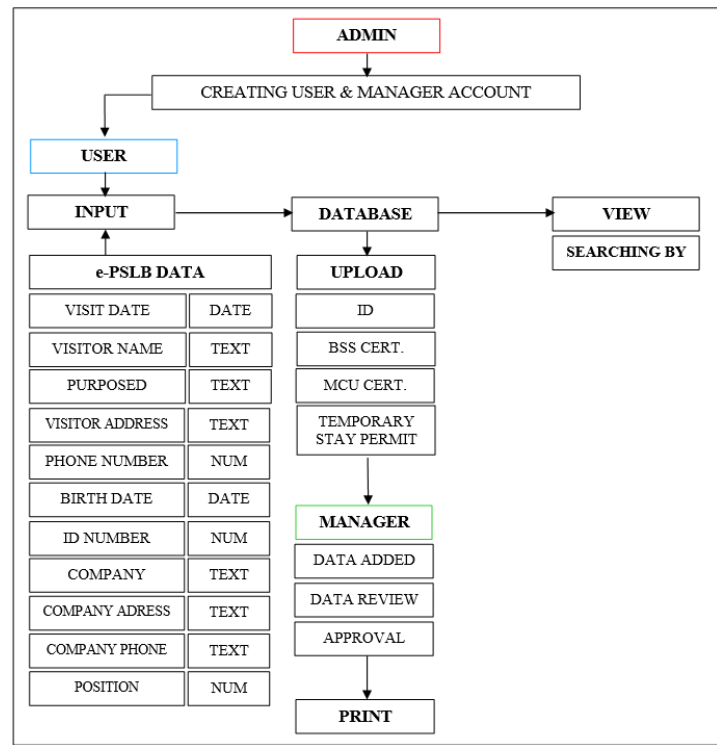

Figure 3. Process of e-PSLB.

2. Process 2 (User) is the submission process of e-PSLB data by User including visit date, visitor name, purposed, visitor address, phone number, birthdate, ID number, company, company address, company phone position, then upload to data base including ID Scan, Basic Sea Survival (BSS) certificate, Medical Check Up (MCU) certificate and temporary stay permit for the foreigner.

3. Process 3 (Manager) is process of review and approval data by manager (HSSE Manager, operation \& Maintenance Manager and Marine Operation Manager).

User Interface (UI) design aims to provide an overview of the application to be built, which utilized to provide an overview for potential application users. In addition, by designing the interface is expected to facilitate the implementation and facilitate the system developers in building applications. Design process of E-PSLB and examples of e-PSLB UI design shown in Figure 3,4, and 5.

3) Implementation and Testing

a. Unit Implementation

The first step in the implementation process, is to provide access to users who are willing to use the application. The user is a PGN LNG worker who will on board to the FSRU.

1. Hardware

Hardware requirements used this system is Desktop PC with the specifications are as follows:

a. Processor: Intel@ Core (TM) i3-370M CPU@2.10GHz

b. Operating system: Windows 8 32-bit

c. RAM: $2.00 \mathrm{~GB}$

d. Mouse and Keyboard Standard

2. Software

The software used in implementing the system is a desktop-based web browser, both Chrome, Mozilla, Opera, and more. 


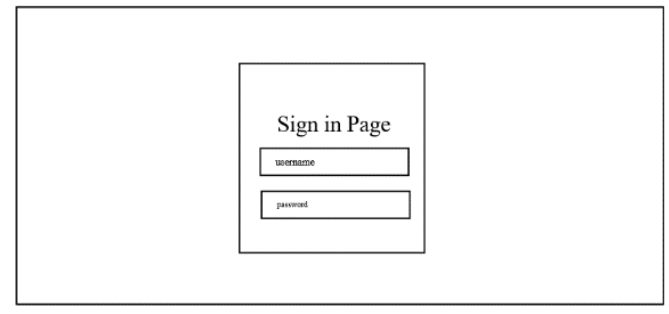

Figure 4. Sign in page design.

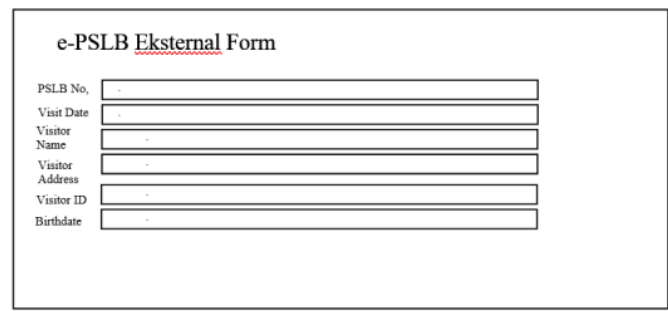

Figure 5. e-PSLB submission form.

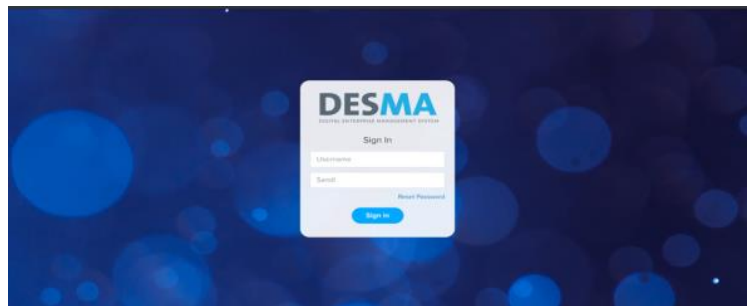

Figure 6. Sign in Display.

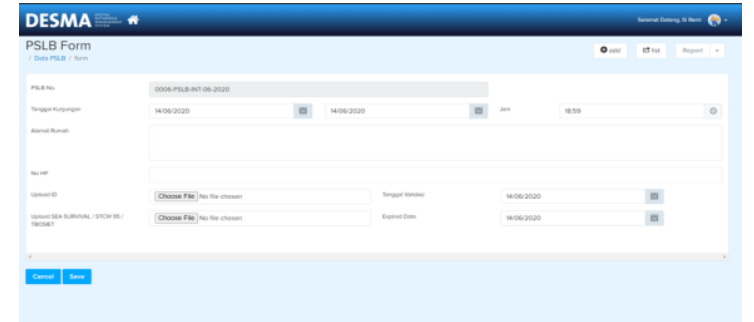

Figure 7. e-PSLB Form Display

Table 2.

Calculation of Manpower per e-PSLB

\begin{tabular}{clll}
\hline \hline No. & \multicolumn{1}{c}{ Menu } & \multicolumn{1}{c}{ Expected results } & Test results \\
\hline 1 & Sign in Page Test & Show the option of logging account in as Admin, Manager or user & Successful \\
2 & Use $\quad$ Registration & Add a new account & Successful \\
& Testing & Add Applicant Information & Successful \\
3 & Add e-PSLB form & Display approval on submitted application & Successful \\
4 & Approval Data & Displaying QR Code on Approval & Successful \\
5 & Generate QR Code & Approval print out in PDF form & Successful \\
6 & Print PDF & Sign out account & \\
7 & Sign Off Page Test & &
\end{tabular}

Table 3.

Total of PSLB Data

\begin{tabular}{|c|c|c|c|}
\hline No. & Years & PSLB Data & Total \\
\hline \multirow[t]{2}{*}{1} & 2017 & Internal & 24 \\
\hline & & External & 229 \\
\hline \multirow[t]{2}{*}{2} & 2018 & Internal & 21 \\
\hline & & External & 233 \\
\hline \multirow[t]{3}{*}{3} & 2019 & Internal & 18 \\
\hline & & External & 321 \\
\hline & & & 846 \\
\hline
\end{tabular}

3. Implementation of Design Interface

e-PSLB interface when executed will be shown in Figure 6 and 7.

a. Testing Application

Testing at this stage intends to test the application and ensures that the application can run as intended and all functions can be used. Testing done using the Black-box method. The Black-box testing is a test that focuses more on the functionality of the application and the test success rate is measured from the fulfilment of the purpose of the function already created.

b. Testing functionality

Testing the application is made in the form of a black box testing table of functions in the application. Table 1 shows test results of the functions contained in the application.

Based on the results of the functionality test that has been done can be concluded that the application is running well, but does not close the possibility of error can occur at some time the application is used. So, it requires maintenance process to better know the shortcomings of the application. (Shown on Table 2)

\section{4) System Testing and Integration}

After test and integration, e-PSLB Application have been completed within 6 months so that they are complete until the end of 2016. Then 2-month socialization and the trial period conducted to all stakeholders in the operational area, both internal and external. (Shown on Table 3 and 4)

\section{RESULT AND DISCUSSION}

\section{A. Efficiency and Discussion}

In July 2016, Department HSSE has been developed an ePSLB Application that started to be implemented in January 2017. Until December 2019 it has already done 846 PSLB submissions with an average 282 per year. Based on the analysis of the data, it showed that if still using manual PSLB Registration in the period of January 2017 until December 2019 it is required total cost of Rp. 333,630,000 in three years. Whereas when compared with the use of ePSLB within same period, it is required a total cost of Rp176,846,741. In addition, reviewed from the completion duration of one Manual PSLB takes 3 hours 15 minutes, 
Table 4.

Calculation of Manpower per e-PSLB

\begin{tabular}{|c|c|c|c|c|c|c|}
\hline & $\begin{array}{c}\text { Est. } \\
\text { Monthly Salary } \\
\text { (IDR) }\end{array}$ & $\begin{array}{l}\text { Hourly } \\
\text { Fee } \\
\text { (IDR) }\end{array}$ & $\begin{array}{c}\text { PSLB } \\
\text { Duration } \\
\text { (Hours) }\end{array}$ & $\begin{array}{c}\text { Manpower } \\
\text { Cost per PSLB } \\
\text { (Daily/ IDR) } \\
\end{array}$ & $\begin{array}{c}\text { e-PSLB } \\
\text { Duration } \\
\text { (Hours) }\end{array}$ & $\begin{array}{c}\text { Manpower Cost } \\
\text { per e-PSLB } \\
\text { (Daily) }\end{array}$ \\
\hline Admin & 5.000 .000 & 28.409 & 1 & 28.409 & 0 & - \\
\hline Passenger & 8.000 .000 & 45.455 & 0,75 & 34.090 & 0,25 & 11.364 \\
\hline HSSE Manager & 30.000 .000 & 170.455 & 0,5 & 85.227 & 0,17 & 28.409 \\
\hline Marine Operation Manager & 40.000 .000 & 227.273 & 0,5 & 113.636 & 0,17 & 37.879 \\
\hline Head of Operation Division & 45.000 .000 & 255.682 & 0,5 & 127.841 & 0,17 & 42.614 \\
\hline Total & & & 3,25 & 389.205 & 0,75 & 120.265 \\
\hline
\end{tabular}

Table 5.

Breakdown Cost

\begin{tabular}{ccc}
\hline \hline & PSLB & (Yearly) \\
\hline e-PSLB Program Set & - & e-PSLB (Yearly) \\
Paper Cost & $8,460,000$ & - \\
Program Maintenance & - & $20,000,000$ \\
Manpower Cost & $102,750,000$ & $31,750,000$ \\
Total & $111,210,000$ & $93,346,741$ \\
Total Cost (3 Years) & $333,630,000$ & $176,846,741$ \\
\hline \hline
\end{tabular}

while e-PSLB only takes 45 minutes. Therefore, based on the results of the analysis of e-PSLB proved effective and efficient in assisting operation excellence of PGN LNG.

\section{B. E-PSLB Challenge in The Future}

As part of the Industrial Revolution 4.0, every organization and company are demanded to bring innovations to remain competitive and be able to streamline every business process so that it runs quickly and effectively. The application of digitalization to the submission of the Personal Safety Logbook (PSLB) greatly helped the process that previously took several days to become only a few minutes. In connection with the ongoing development currently related to data collection Personal Safety Logbook (e-PSLB) is a concept that focuses on digitizing in real-time for policy making related to permits to go to the FSRU and utilizing big data raising situational awareness and decision making. In this case, e-PSLB is clearly a "supporting technology".

\section{CONCLUSION}

Throughout the years PGN LNG always develop and evaluate company performances, including registration process for personnel on board FSRU. Which based on result of cost efficiency and completion duration from manual PSLB to e-PSLB, it found that e-PSLB could reduce cost consumption and completion duration significantly. From cost perspective, it reduces cost consumption from $\mathrm{Rp}$ $333,630,000$ in three years to $\mathrm{Rp} 176,846,741$ in three years or equal to efficiency of $47 \%$. Meanwhile from completion duration of PSLB, it enables reduction of completion duration from 3 hours 15 minutes to 45 minutes or equal to $76 \%$ reduction of completion duration time. In addition, ePSLB is also reduce cost by remove necessity of an admin which replaced by its online system.

e-PSLB is obtained by the development model on Waterfall model that starts from the early stages of the development of the system until the final stage of system development on the maintenance phase. The next stage will not be implemented before the previous stage is completed and cannot return or repeat to the previous stage. Therefore, it could enhance features that required from various function that involves for personnel role on board FSRU.

Other factors to be developed from e-PSLB is its features to be more update based on Industrial Revolution 4.0, which one of them to enhance new features for increasing easiness of person on duty to complete assessment and review of ePSLB. Which including but not limited to ease access of ePSLB if it's in low signal area and alarm reminder that integrated to mobile device.

\section{REFERENCES}

[1] R. Morrar, H. Arman, and S. Mousa, "The Fourth Industrial Revolution (Industry 4.0): A Social Innovation Perspective," $J$. Technol. Innov. Manag. Rev., vol. 7, no. 11, pp. 12-20, 2017.

[2] J. Nagy, J. Oláh, E. Erdei, D. Máté, and P. J., “The Role and Impact of Industry 4.0 and the Internet of Things on the Business Strategy of the Value Chain-The Case of Hungary," J. Sustain., vol. 10, no. 3691, pp. 1-25, 2018.

[3] Y. Marbun, R. Isnanto, and K. T. Martono, "Pembuatan Aplikasi TOEFL sebagai Media Pelatihan Bahasa Inggris Berbasis Web," $J$. Teknol. Dan Sist. Komput., vol. 4, no. 1, p. 83, 2016. 